\title{
Mathematical Game Creation and Play Assists Students in Practicing Newly-Learned Challenging Concepts
}

\author{
Kalyn Jon Cody ${ }^{1}$, Audrey C. Rule ${ }^{2}$, Benjamin R. Forsyth ${ }^{3}$ \\ ${ }^{1}$ Hubbell Elementary School, Des Moines, IA, USA \\ ${ }^{2}$ Department of Curriculum and Instruction and Center for Educational Transformation, University of \\ Northern lowa, Cedar Falls, IA, USA \\ ${ }^{3}$ Educational Psychology and Foundations, University of Northern lowa, Cedar Falls, IA, USA \\ Email: kalyn.cody@dmschools.org, audrey.rule@uni.edu, benjamin.forsyth@uni.edu
}

Received 25 June 2015; accepted 4 August 2015; published 7 August 2015

Copyright (C) 2015 by authors and Scientific Research Publishing Inc.

This work is licensed under the Creative Commons Attribution International License (CC BY).

http://creativecommons.org/licenses/by/4.0/

(c) (i) Open Access

\section{Abstract}

Twenty-four high-performing fifth grade students (aged 10 - 11 years) participated in a year-long study in which conditions alternated for six instructional units between lecture-based mathematics instruction and practice through solving additional problems in small groups versus practice through designing and playing mathematics games related to the topic. Students scored similarly on all units at the time of the posttest. Creating games allowed students to examine concepts on their own, making sense of them at a deeper level, avoiding confusion. Game-making may also have made the mathematics more personal, relevant, and interesting. The authors suggest that mathematics teachers consider adding game-making to their strategies for practicing and applying mathematical concepts.

\section{Keywords}

Instructional Games, Motivation, Student Choice, Mathematics

\section{Introduction}

Many educators avoid spending precious instructional time allowing students to creatively invent and play games to practice mathematical concepts because they believe that more direct instruction or student small group work in solving and discussing given problems will lead to greater learning gains (Au, 2007). To determine if this is indeed the case, the researchers conducted a repeated measures study with upper elementary stu- 
dents for six relatively new mathematics topics. Students alternated between more self-directed methods that involved game-making followed by game-playing and more teacher-centered methods of additional instruction followed by small group practice of given problems. This research design allowed the researchers to assess student mathematical performance and attitudes for each condition. The following sections briefly review the literature on self-directed learning, inquiry and learning through play, and previous use of student game-making in learning mathematics.

\subsection{Self-Directed Learning and Self-Regulation}

When students are provided opportunities to take control of and evaluate their own learning, they learn the valuable skill of self-regulation (cf., Bandura, 1989; Zimmerman \& Schunk, 2004). The literature on self-directed learning and self-regulation supports the use of games and other playful activities in classrooms regardless of students' prior achievement levels and motivation (Oblinger, 2004). Self-regulation depends upon learners being able to set their own goals and standards for performance; therefore, students need opportunities to practice these abilities (Winne, 1995). Creating personalized games related to mathematical concepts is inherently a goal-setting and standard-building behavior. Another aspect of assisting students in becoming more self-directed is providing students opportunities to evaluate their final products (Butler \& Winne, 1995), as well as imposing consequences for their behavior (Miller \& Brickman, 2004). When students are given opportunities to design playful activities in the classroom as a means of learning content, they evaluate their creations as they engage in the activity. Furthermore, the rules of the game or activity provide a set of self-imposed contingencies that provide necessary consequences and feedback for learning.

\subsection{Inquiry and Learning through Play}

Many studies have shown the benefit of play in educating young students (e.g., Ailwood, 2003; Isenberg, 2002; Moyer, 2014). The benefits cited in these studies include, among others, the development of fine and gross motor skills, interpersonal communication, negotiation, stress reduction, goal seeking, cognitive development, and problem solving. Nevertheless, American school districts continue to focus on direct academic instruction for test performance, excluding most imaginative pretend play and “choice” time from kindergarten and classes for older students (Miller \& Almon, 2009). Clear articulation of how the cognitive skills children develop during pretend or structured play impact future learning more than merely memorizing standardized information is crucial to keeping play from being excluded from school (Bergen, 2002). Another factor preventing the use of play in classrooms is the belief many teachers hold that play and learning are two separate concepts that are mutually exclusive (Hyvonen, 2011). This might be true if play were viewed as a strictly imaginative, no rules, free-forall. "Affording play" (play with elaboration and assessment), in which the teacher acts as facilitator, advisor, observer, and encourager, bridges the gap between play and learning (Hyvonen, 2011). The use of affording play in the form of student-made mathematical games during this study may help to define benefits for highachieving students.

\subsection{Games in Mathematical Education}

Use of games in teaching mathematics is considered a best practice (Moore, 2012) that is recognized by students as making mathematics more meaningful (Miller, 2009). Games encourage logico-mathematical thinking (Kamii \& Rummelsburg, 2008), facilitate the development of mathematical knowledge while having a positive influence on the affective component of learning situations (Booker, 2000), and have a positive effect on students' interest and motivation (Bragg, 2007). For example, teachers using commercial games to increase understanding of algebra, spatial sense, and multistep problem solving found that students were highly motivated and engaged during game-playing (Lach \& Sakshaug, 2005). Additionally, elementary school students in Queensland who played probability games not only exhibited enjoyment and motivation, but developed more positive attitudes toward the utility of learning about chance with decreased mathematics anxiety related to the topic (Nisbet \& Williams, 2009).

Computer technology has allowed simple mathematical games to become more customized, variable, and personal. This variability has allowed games to become more effective in exposing students to more problems per day than simple worksheets allowed (Lee, 2004), in addition to providing immediate feedback and appropri- 
ate follow-on problems. Lee (2004) also found that these seven to eight-year-old students routinely increased the difficulty in their games without direct instruction to do so, suggesting that computer games motivated students to take risks in practicing mathematics concepts. Computer games, more than two decades ago, produced significant gains in mathematics achievement for k-12 students (Randel, Morris, Wetzel, \& Whitehill, 1992).

Besides playing commercial or teacher-made games, students obtain many benefits from designing their own games. The Playground Project (Noss \& Hoyles, 2006) was a research endeavor in which young students interacted in an online environment across countries in building, modifying, sharing, and playing mathematical computer games. The project directors found that even young students could learn how to modify the rules of a virtual reality environment without direct instruction; for example, students learned how formally state rules to do things like change the color of objects, move spaceships, and to produce a sound when a bat hit a ball. Many students made advanced mathematical discoveries for their young age such as the fact that two-dimensional motion could be decomposed into horizontal and vertical components. Engaging students in using computer tools and objects allowed students to translate standard mathematics concepts into personal knowledge constructions.

Student-made games have been utilized in many contexts to assist students in developing deeper mathematical understandings. Secondary mathematics teachers derived content knowledge of the history of mathematics along with pedagogical knowledge through game creation (Huntley \& Flores, 2010). In another study, university freshmen designed and played their own games to learn mathematics concepts in pre-calculus and calculus courses (Gallegos \& Flores, 2010). These two studies were descriptive reports of how game-making was incorporated into these innovative courses rather than controlled experiments comparing student performance with and without game-making and playing. Therefore, to better compare the effects of student-centered game-making versus more teacher-centered instruction and small group working of given problems, a small research study was conducted with upper elementary students.

The games developed by fifth grade students, which were explored in the current study, were primarily cardand board-based. Students first examined and played some teacher-made games to become familiar with various formats for games. Then, the teacher gave the students instruction on how to make games variable from play to play, how to design them to be easier or more difficult, and how to allow the game story or actions to develop through the experience of playing. These factors allowed the games to behave more like modern computer games, while still being simple enough for students to build in a few days with items regularly found in a classroom. Fengfeng (2008) reported that many games that are commercially available lack connection to the curricular goals that students need to meet to succeed in our current climate of high-stakes testing. Our students' games had the advantage of requiring the students to design each of the mathematics standards from the current topic into their play.

To determine the effects on enjoyment, motivation, perceived understanding and mathematical performance of students creating and playing their mathematical games related to the topic, we designed a repeated measures study. The same group of fifth grade students (aged 10 - 11 years) alternated between two conditions so that their performance and attitudes related to topics studied under one condition could be compared to those studied under the other. Repeated measures research design is especially effective in controlling the following potential threats to internal validity: selection of research subjects, maturation of students, loss of subjects, or regression (Creswell, 2002). The treatments were designed to be distinct (use of game-making followed by game-playing for practice versus additional teacher instruction followed by small group solving and discussion of problems) and the treatment periods were fairly short (a few weeks), making this within-group research design effective.

We hypothesized that the experimental condition in which students spent time creating games, and then practicing mathematics by playing the games designed by other groups of classmates would be more enjoyable and motivating, with better perceived student understanding of concepts and higher resulting mathematical performance scores compared to the control condition of additional teacher instruction and solving/discussing problems in small groups. Details of the methodology are provided in the next section.

\section{Method}

\subsection{Participants}

Fifth grade students ( $\mathrm{n}=24$; 16 male, 8 female; 18 White, 3 Black, 3 Biracial), aged 10 or 11 years, who had shown advanced performance in mathematics and who were enrolled in a mathematics class that addressed the sixth grade mathematics curriculum at a suburban school district in the Midwestern United States participated in 
the study. Internal review board approval from the overseeing university, school district approval, and both student and parent or guardian written consent were obtained for all study participants.

\subsection{Research Design}

The study was completed over the course of an entire school year with six main mathematics topics that the instructor judged as presenting new mathematical concepts, rather than review, being chosen for inclusion in the study and randomly assigned to the conditions. The other, more review-focused mathematics topics addressed during the school year were not included as part of the study. A pretest-posttest repeated measures design was used in which the same group of fifth grade students alternated between a control condition for learning the mathematics topic through small group working of problems with discussion and an experimental condition that utilized student-made games to practice concepts. The advantage of this repeated measures research design was that comparisons were made with the same group of students and the same enthusiastic teacher with mathematics instructional units that each lasted approximately the same number of days.

Each mathematics unit began with students responding to the school district's benchmark assessment pretest. Then, the same instructor presented interactive lessons on the mathematics. During the last three days of this instruction, students experiencing the experimental condition designed their mathematical games in small groups, whereas students experiencing the control condition continued to receive interactive instruction from the teacher regarding the current mathematical topic. Students subsequently practiced the mathematics in one of two ways: 1) through the more-conventional method of solving and discussing a given set of practice problems (control condition), or, 2) through playing student-made mathematics games that addressed the topic and provided student-generated practice problems to be solved with a correct answer key (experimental condition). After students had practiced the concepts for five class periods, they completed the school's benchmark posttest assessment. In the games unit condition, students created and played games of other groups during those five class periods. In the non-games unit condition, those five class periods were spent with students working in small groups to practice new problems with additional instruction from the teacher as needed or requested. The design of the study is shown in Table 1.

\subsection{Instrumentation}

All students took the district-provided identical pretest and posttest (district benchmark assessments) for each mathematics unit. These tests were mostly constructed response (only a few multiple choice questions throughout the 6 units) and were between 10 - 15 questions each (the exception is the decimal operations unit; that test was 20 questions and over half of it was multiple choice). The tests were tied to the state standards for mathematics for each topic and devised by the school district.

Each student responded to a quick student attitude survey after completing the practice work on each unit (the group work problems or the creation and playing of games). This survey consisted of three questions answerable by circling a number on a rating scale that went from 1 to 10 . Students were asked to "Please circle a number below to rate: 1) your enjoyment of mathematics during the unit we just completed; 2) ... your understanding of this mathematics topic; and 3) ... how motivated you felt to learn more about the mathematics during this unit. On the scale, " 1 " signified "not enjoyable at all," or "did not understand at all," or "not motivated at all”; and "10" signified "very enjoyable," or "understood it very well” or "very motivated”. Students were asked to

Table 1. Design of the pretest-posttest repeated measures study.

\begin{tabular}{ccc}
\hline Order & Approximate Months of School Year & Mathematical Topic of Unit \\
\hline 1 & August to September & Ratio and Proportional Relationships \\
2 & October to November & Multiplication and Division of Fractions \\
3 & November to December & Multiplication and Division of Decimals and Percent \\
4 & January to February & Data and Statistics \\
5 & February to March & Geometry \\
6 & April to May & Expressions and Equations \\
\hline
\end{tabular}


give two reasons for each of their responses. All student responses to a question for each condition were transferred to a spread sheet and sorted using the constant comparison method in which similar responses were grouped into categories while simultaneously comparing all the responses to the given question. The categories were repeatedly refined as new responses were read, changing the category labels to define new relationships as needed (Dye, Schatz, Rosenberg, \& Coleman, 2000).

\section{Results and Discussion}

\subsection{Pretest and Posttest Scores}

Pretest and posttest mean scores are shown in Table 2. Students performed just as well for each condition on the posttest scores as evidenced by similar posttest scores (no significant differences were found). This indicates that students spending time to create and play games related to the mathematical content being taught results in similar performance to more conventional small group solving of mathematics practice problems.

\subsection{Student Attitudes}

Table 3 shows the mean attitude ratings for the game and non-game units. Overall, the scores were fairly high for all ratings, regardless of the condition. This reflects student appreciation for their enthusiastic teacher who enjoyed teaching mathematics and who invested a lot of time in his instruction. Differences in mean ratings across conditions were non-significant. Understanding for both conditions was perceived similarly and reported to be higher than enjoyment or motivation. This finding is congruent to student posttest scores that were similar for games and non-games units. It was no surprise that enjoyment was lower than understanding, but it was a bit odd that the enjoyment was as high as it was, compared to attitudes in the general school population regarding mathematics (Furner \& Duffy, 2002). The students in the current study were somewhat advanced in mathematics, taking sixth grade mathematics in fifth grade. They likely felt more competent in mathematics than typical students and this feeling of competency correlates with self-motivation (Deci \& Ryan, 2010). This enjoyment indicates the relatively high levels of motivation of this advanced group, as, in general, humans seek that which brings them pleasure.

In general, the reasons students gave for their ratings on the attitude surveys were brief and surprisingly similar. Table 4 shows the mean student ratings of enjoyment for the game compared to the non-game units, along with reasons for these ratings. Fewer students mentioned liking the game unit topics (line 4), but students in both conditions expressed that they found the unit work (game and non-game) to be fun. This finding indicates that although topics may not be perceived as interesting, creation of games may transform the learning into an enjoyable activity. During the games units, students more often reported enjoying the unit for being challenged (line 6).

The students most often reported, in both the games and non-games units, the reason for their lack of enjoyment as boredom. Students in the non-games units also reported fairly frequently that they did not enjoy the unit

Table 2. Student scores (out of a possible 100 points) on mathematics content assessments comparing units in which games were used or not used.

\begin{tabular}{ccc}
\hline Assessment & $\begin{array}{c}\text { Mean Score of Units with Practice through Inventing } \\
\text { Games (Experimental Condition) }\end{array}$ & $\begin{array}{c}\text { Mean Score of Units with More-Conventional Small } \\
\text { Group Practice (Control Condition) }\end{array}$ \\
\hline Pretest & $52.4(11.7)$ & $64.8(14.3)$ \\
Posttest & $87.3(6.4)$ & $87.0(9.3)$ \\
\hline
\end{tabular}

Table 3. Attitude ratings for game and non-game units.

\begin{tabular}{|c|c|c|}
\hline Attitude & Game unit mean rating & Non-game unit mean rating \\
\hline Enjoyment of mathematics during lessons & $7.9(1.5)$ & $7.6(1.8)$ \\
\hline Understanding of this mathematics topic & $8.8(1.2)$ & $8.8(1.4)$ \\
\hline Motivation to learn more about the mathematics of the unit & $7.9(1.7)$ & $7.8(2.0)$ \\
\hline
\end{tabular}


because it was difficult or frustrating (line 2). This finding contrasts with the pretest scores that showed the game units were initially more difficult for students, indicating that making games to practice difficult concepts was more interesting and less frustrating than practicing concepts through more conventional discuss-and-solve methods.

\subsection{Perceived Student Understanding of Mathematics}

Table 5 shows that students in the games units most often reported understanding of the material by commenting that the material was easy or that they had significant prior knowledge (line 2). This rating is interesting when contrasted with the struggle students displayed on the unit pre-assessments and the fact that students frequently reported their final proficiency with the material. Students most often discussed understanding in the non-games units by stating that the concepts made sense and that the teacher explained ideas well (lines 3 and 4).

\section{Table 4. Frequency of top reasons for rating enjoyment of units.}

\begin{tabular}{lcc}
\hline \multicolumn{1}{c}{ Reason Given for Lesson Enjoyment } & Game Units Mean Number of Reasons & Non-Game Units Mean Number of Reasons \\
\hline Activities were fun & 7.3 & 10 \\
New learning & 4.7 & 6.5 \\
Easy work & 5.7 & 4.5 \\
Liked topic & 1.7 & 0 \\
Liked game making & 6.0 & 1 \\
Work was challenging & 4.3 & 2.5 \\
I reached proficiency & 2.0 & 1.5 \\
The topic or problems were interesting & 2.3 & 4.5 \\
\hline Reasons Given for Lack of Enjoyment & & 5.5 \\
of Lessons & & 0.5 \\
Boring, redundant or already mastered & 2.7 & 2 \\
Concepts were difficult or frustrating & 1.3 & 2.7 \\
Not proficient or no prior knowledge & 0.7 & \\
Work was confusing & & \\
\hline
\end{tabular}

Table 5. Frequency of top reasons for rating understanding of units.

\begin{tabular}{lcc}
\hline Reason Given for Lesson Understanding & Games Units: Mean No. Reasons per Unit & Non-Games Units: Mean No. Reasons per Unit \\
\hline Proficient in concepts & 7.7 & 6 \\
Easy to learn & 8.3 & 3.5 \\
Concepts made sense & 4.3 & 7 \\
Teacher explained concepts well & 3.7 & 3 \\
New learning occurred & 7.3 & 3.5 \\
Liked topic & 1.3 & 9 \\
\hline $\begin{array}{l}\text { Reason Given for Lack of Understanding } \\
\text { of Lessons }\end{array}$ & & 2.5 \\
\hline Confusion & 0.3 & 1 \\
Lack of proficiency & 6.3 & 9 \\
Already mastered & 0.0 & 7 \\
\hline
\end{tabular}


Students in the non-games unit more frequently reported confusion or difficulty of the material as the reason for less understanding of the unit. In contrast, students in the games units connected any lack of understanding to a lack of proficiency in solving problems.

\subsection{Student Motivation}

Table 6 shows that the most commonly remarked reason for high motivation during all units was new learning. High achieving students are often motivated by gaining knowledge and this group was no different. Again, students expressed greater liking for the mathematical topics of non-games units, but somewhat more frequently noted the games units as being fun.

The bottom part of Table 6 confirms the previous finding that students thought the material of the non-games units was more confusing and difficult, even though they scored higher on the pretests of these topics. Creating games may have allowed students to examine concepts on their own, making sense of them at a deeper level, avoiding confusion.

\subsection{Student-Created Games}

Students worked in small groups of two to four persons to create the games. The self-chosen groups varied from unit to unit and were mostly same-sex groups, but mixed groups occurred occasionally. The simplest games made by students involved rolling dice or drawing a card to fill in a portion of a number sentence that a player had to then solve to score points. Occasionally, these games pitted players against each other or against a clock in a race. These simple games appeared in each of the games units, but after the first games unit they became less frequent as students noticed other game possibilities and began to increase the complexity of their games.

The second type of game included a wide array of board games. Some of these were very basic games in which a player rolls a die, moves around a board, and encounters various obstacles and benefits on different spaces. Examples of this type of game made by students are shown in Figure 1 and Figure 2.

Some of the board games included elements of game play that had nothing to do with mathematics but were personally motivating to students as they addressed current celebrities with trivia questions, such as a game about the popular music singer, Taylor Swift titled, “The Swift Challenge”. See Figure 3 and Figure 4. These games were quite popular and were the most commonly produced type. One reason the students liked to make this type of game was that they were able to create outlandish concepts with fun features while being able to easily incorporate mathematics review into the play.

Some students took board games to a higher level of complexity. These games often included a board, but the board more resembled a map. The maps included treasure chests, one-way doors, and enemies that were visible

Table 6. Frequency of reasons for rating motivation of units.

\begin{tabular}{|c|c|c|}
\hline Reason Given for Lesson Motivation & $\begin{array}{l}\text { Games Units: Mean No. } \\
\text { Reasons per Unit }\end{array}$ & $\begin{array}{c}\text { Non-Games Units: Mean No. } \\
\text { Reasons per Unit }\end{array}$ \\
\hline New learning & 5.0 & 6.5 \\
\hline Fun & 5.5 & 5 \\
\hline Knowledge would be used in the future & 2.7 & 5.5 \\
\hline Liked the topic & 2.3 & 5.5 \\
\hline Felt determined & 2.7 & 4.5 \\
\hline Easy & 2.7 & 1 \\
\hline \multicolumn{3}{|l|}{ Reason Given for Lack of Motivation } \\
\hline Confusing and difficult & 1.0 & 3.5 \\
\hline Boring or repetitious & 2.0 & 2.5 \\
\hline Little new learning & 3.0 & 2.5 \\
\hline Not interested in the mathematical concepts & 2.0 & 1.0 \\
\hline
\end{tabular}




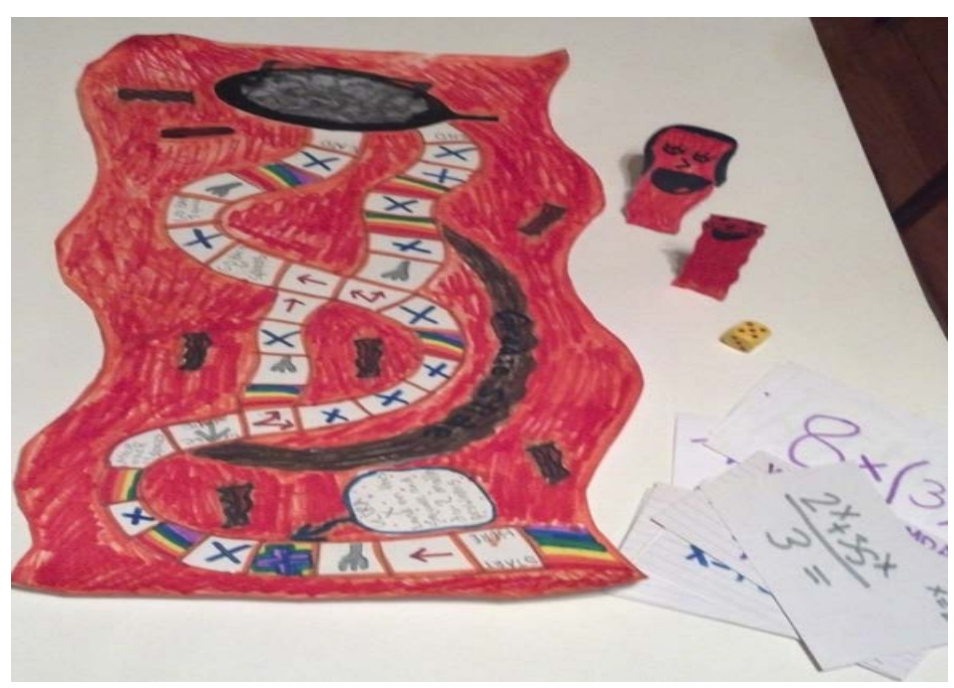

Figure 1. An example of a basic board game titled "bacon maze" with a giant frying pan and grease slide.

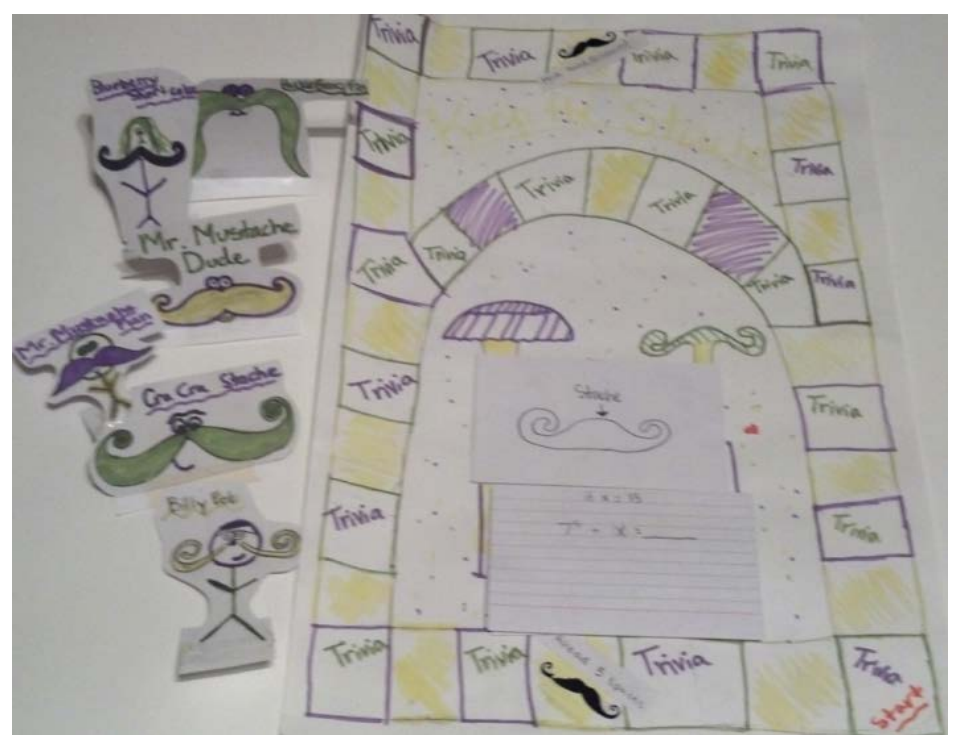

Figure 2. Another example of a basic board game titled "mustache chase”.

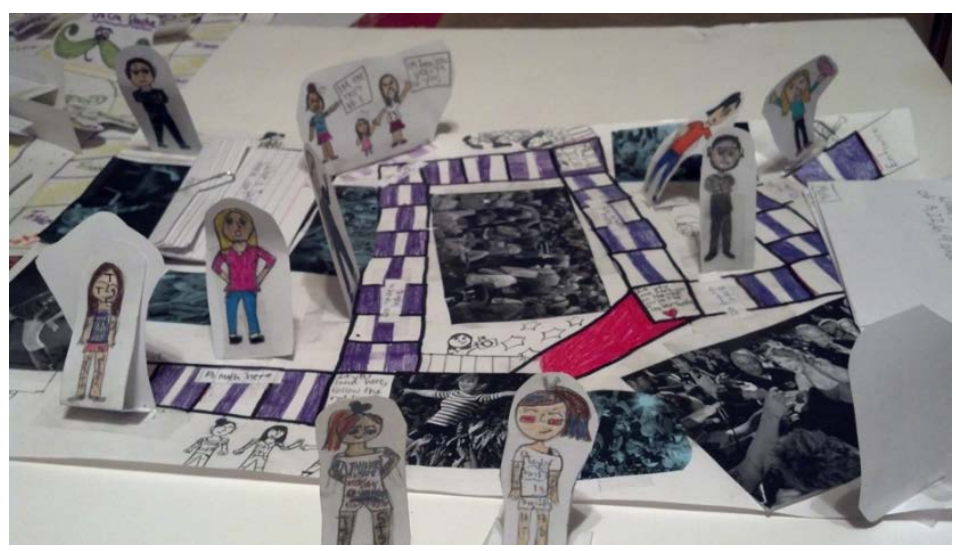

Figure 3. The board and markers for game titled, "the swift challenge”. 


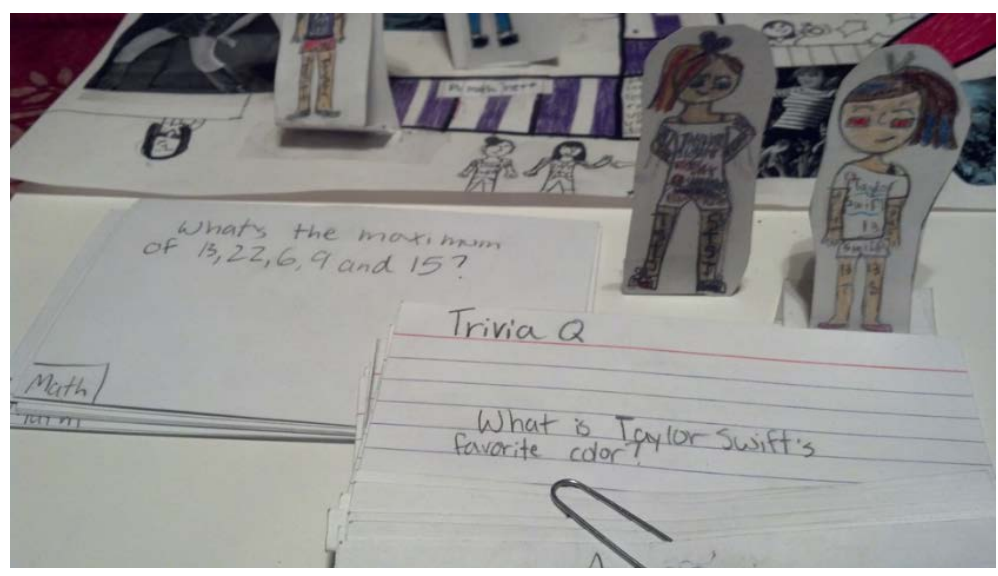

Figure 4. Example trivia and mathematics questions for "the swift challenge".

or hidden. Players chose certain characters with a variety of attributes relating to hit points or strength manifested in the ability to retry missed problems, or many other attributes that the creators invented. Students engaged in these games through adventures or role-playing with correct responses to mathematics problems required to progress to different parts of the map, to defeat enemies, or to obtain treasure and items.

Groups of both sexes produced adventure games, but the themes were different: males created fighting games, while females focused more on games about popular celebrities. The mixed groups generated games like "Mustache Chase" and "Bacon Maze". See Figure 1 and Figure 2. The object of Mustache Chase was to acquire five mustache cards by moving around a board, answering questions. The Bacon Maze game featured a labyrinth in which the player chose different paths with hazards such as stoves or frying pans that stopped the player who could not answer the math questions correctly. This game included the opportunity to earn bonus cards for skipping a space by answering mathematics questions at special spaces. The humor and absurdity students incorporated into games like these added to the joy of the activity.

The most complex games were a series of choose-your-own-adventure type games during the final games unit. Several groups of students were interested in making video games for their last unit, but found quickly that they would need far more time than a few days to produce something with variability and enough mathematics review to fit the project requirements. Instead, students developed a plan to put the game on a website with links that would lead from point to point with a variety of challenges embedded throughout. However, building websites also proved to be too time-consuming. Students settled on using PowerPoint as the foundation of their games with hot buttons that jumped from slide to slide as a player made decisions. Students produced a football game, a fishing game, and a treasure hunting game. These games were intricate and fairly massive. "Treasure Hunter" had 45 slides and was highly enjoyed by students with good replay value. Several slides from this game are shown in Figure 5.

Students displayed creativity, attention to detail, and thoughtfulness in meshing mathematics review with fun, innovative games. Some games were simple, some were complex, but all were valuable in helping the students in this class master difficult mathematics concepts. As students designed the games, they discussed how to make the game more challenging for the mathematics being addressed. Therefore, they were mentally reviewing the concepts and deciding which concepts were more difficult (metacognition) and should be incorporated into some "challenging" questions.

\section{Conclusion}

Students in this study reached the same levels of mathematical achievement by practicing concepts through creating and playing games as with more-conventional solving of practice problems. Although students found the topics of the games units more difficult initially (as evidenced by pretest scores) and less interesting (as acknowledged on the attitude survey), they reported much less frustration and confusion along with more ease of learning and more fun during the units in which students practiced with games. These findings indicate that allowing students the time to create and play each other's games is at least as effective as more-conventional group practice and seems to have additional benefits of less frustration and greater student clarity of concepts. 

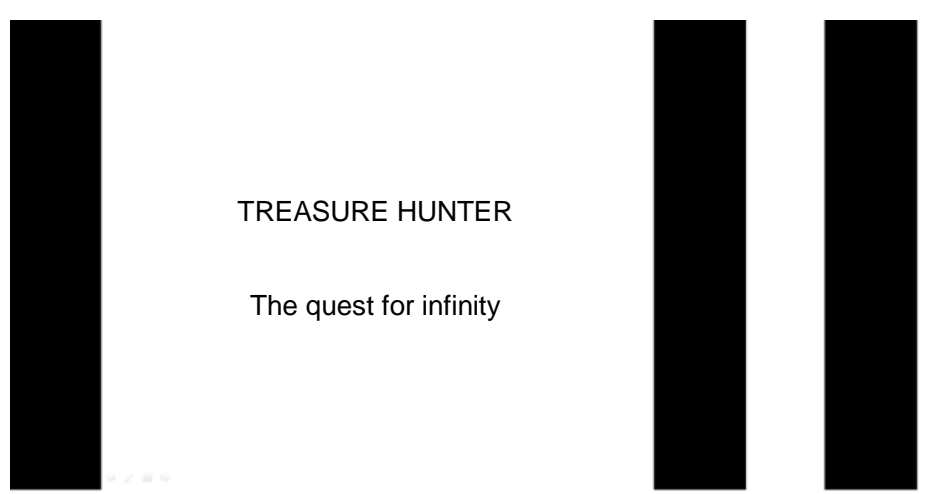

SUCCESS

TREASURE HUNTER

The quest for infinity

EPIC JUMP MATH

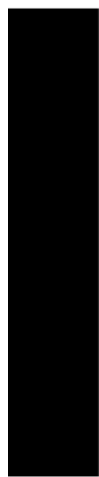

C:34

A:84 B:39

$x=6$
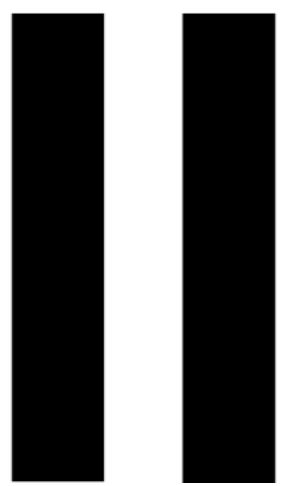

You are freed now do you want to sit there or go over to the door?

wait

walk to the door

GO TO THE MIDDLE

You are slowly crushed by walls closing in restart

Figure 5. Example slides from a game using Powerpoint.

Many teachers across the globe feel great pressure to prepare students for standardized tests, often resorting to direct instruction and drill in mathematics rather than more student-centered approaches. The current study shows that having students create games with clear guidelines for required content can be just as effective and may produce additional benefits of deeper understanding.

Ultimately, it may have been the elements of student choice and self-direction that make the difference. Creation of one's own problems to solve, the selection of how to apply the mathematical concepts, incorporation of preferences for celebrities, or parody of popular games actively involved students in considering the essential aspects of the mathematical concepts and how to incorporate them in into a game in their own way. When asked, students said that they liked "being able to create things", and "trying to outsmart each other with harder and harder math problems". This ownership, along with dissection of the mathematical concepts so that they might be applied in the games, motivated students and allowed them to perceive the learning as fun and easy, whether they initially thought the topics were interesting or not.

The results that emerge from this study indicate that there is certainly room in mathematics education for games, creativity, and developmental play at the upper elementary levels. In addition to students reporting enjoyment of the process of creating and playing the games, the gains they made between the pretest and posttests when compared to the non-game units were evident with large effect sizes. The pretest scores for the games units were significantly lower than for the non-game units, yet students achieved at the same level on the posttests.

The authors encourage mathematics teachers to use student-invented games in their instruction. Students in the current study were focused and engaged during the game-making process. They tried to generate more and more creative set-ups as the year progressed. Games evolved from simple dice, card, and coin-flip games to expansive board games, adventure games with combat (e.g. enemies were damaged when students were able to solve problems), and even a few "choose your adventure" PowerPoint-based games with active links. Students looked forward to building games during each unit. This level of student engagement is hard to achieve in our schools, especially during mathematics.

The authors suggest that additional studies be conducted in using student-made games with students who are less proficient in mathematics. Because a game has rules, protocols, props, or paths along a board, the structure 
of the game may carry some mathematical procedures that are difficult for a student to keep in working memory. Therefore, the student may perform at higher levels with the support of the game, allowing the student to practice and gain more mathematical proficiency. The metacognitive aspects of choosing problems for games and the motivational impact of choosing a game theme that includes interesting characters or ideas related to favorite leisure activities will have a positive effect on learning.

\section{Acknowledgements}

The authors thank the Center for Educational Transformation at the University of Northern Iowa, Cedar Falls, Iowa, USA for support of this project.

\section{References}

Ailwood, J. (2003). Governing Early Childhood Education through Play. Contemporary Issues in Early Childhood, 4, 286299. http://dx.doi.org/10.2304/ciec.2003.4.3.5

Au, W. (2007). High Stakes Testing and Curricular Control: A Qualitative Metasynthesis. Educational Researcher, 36, 258267. http://dx.doi.org/10.3102/0013189X07306523

Bandura, A. (1989). Human Agency in Social Cognitive Theory. American Psychologist, 44, 1175-1184. http://dx.doi.org/10.1037/0003-066X.44.9.1175

Bergen, D. (2002). The Role of Pretend Play in Children’s Cognitive Development. Early Childhood Research \& Practice, 4, Unpaginated.

Booker, G. (2000). The Maths Game: Using Instructional Games to Teach Mathematics. Wellington, NZ: New Zealand Council for Educational Research.

Bragg, L. (2007). Students' Conflicting Attitudes towards Games as a Vehicle for Learning Mathematics: A Methodological Dilemma. Mathematics Education Research Journal, 19, 29-44. http://dx.doi.org/10.1007/BF03217448

Butler, D. L., \& Winne, P. H. (1995). Feedback and Self-Regulated Learning: A Theoretical Synthesis. Review of Educational Research, 65, 245-281. http://dx.doi.org/10.3102/00346543065003245

Creswell, J. W. (2002). Educational Research: Planning, Conducting, and Evaluating Quantitative and Qualitative Research. Upper Saddle River, NJ: Merrill Prentice Hall.

Deci, E. L., \& Ryan, R. M. (2010). Self-Determination. New York, NY: John Wiley \& Sons, Inc. http://dx.doi.org/10.1002/9780470479216.corpsy0834

Dye, J. F., Schatz, I. M., Rosenberg, B. A., \& Coleman, S. T. (2000). Constant Comparison Method: A Kaleidoscope of Data. The Qualitative Report, 4. http://www.nova.edu/ssss/QR/QR4-1/dye.html

Fengfeng, K. (2008). A Case Study of Computer Gaming for Math: Engaged Learning from Gameplay? Computers \& Education, 51, 1609-1620.

Furner, J. M., \& Duffy, M. L. (2002). Equity for All Students in the New Millennium: Disabling Math Anxiety. Intervention in School and Clinic, 38, 67-74. http://dx.doi.org/10.1177/10534512020380020101

Gallegos, I., \& Flores, A. (2010). Using Student-Made Games to Learn Mathematics. PRIMUS: Problems, Resources, and Issues in Mathematics Undergraduate Studies, 20, 405-417. http://dx.doi.org/10.1080/10511970802353644

Huntley, M. A., \& Flores, A. (2010). A History of Mathematics Course to Develop Prospective Secondary Mathematics Teachers' Knowledge for Teaching. PRIMUS: Problems, Resources, and Issues in Mathematics Undergraduate Studies, 20, 603-616. http://dx.doi.org/10.1080/10511970902800494

Hyvonen, P. (2011). Play in the School Context? The Perspectives of Finnish Teachers. Australian Journal of Teacher Education, 36, 65-83. http://dx.doi.org/10.14221/ajte.2011v36n8.5

Isenberg, J. P., \& Quisenberry, N. (2002). A Position Paper of the Association for Childhood Education International. PLAY: Essential for All Children. Childhood Education, 79, 33-39.

Kamii, C., \& Rummelsburg, J. (2008). Arithmetic for First Graders Lacking Number Concepts. Teaching Children Mathematics, 14, 389-394.

Lach, T. M., \& Sakshaug, L. E. (2005). Let’s Do Math: Wanna Play? Mathematics Teaching in the Middle School, 11, 172-176.

Lee, J., Luchini, K., Michael, B., Norris, C., \& Soloway, E. (2004). More than Just Fun and Games: Assessing the Value of Educational Video Games in the Classroom. Late Breaking Results Paper, 24-29.

Miller, E., \& Almon, J. (2009). Crisis in the Kindergarten: Why Children Need to Play in School. College Park, MD: Alliance for Childhood. 
Miller, K. (2009). Real World Math: Views from the Researcher, Teacher, and Student. Senior Thesis, Ypsilanti, MI: Eastern Michigan University.

Miller, R. B., \& Brickman, S. J. (2004). A Model of Future-Oriented Motivation and Self-Regulation. Educational Psychology Review, 16, 9-33. http://dx.doi.org/10.1023/B:EDPR.0000012343.96370.39

Moore, N. (2012). Alternative Strategies for Teaching Mathematics. Education and Human Development Master's Thesis Paper 130. Brockport, NY: State University of New York.

Moyer, M. W. (2014). The Serious Need for Play. Scientific American Mind, 23, 78-85.

Nisbet, S., \& Williams, A. (2009). Improving Students’ Attitudes to Chance with Games and Activities. Australian Mathematics Teacher, 65, 25-37.

Noss, R., \& Hoyles, C. (2006). Exploring Mathematics through Construction and Collaboration. In R. K. Sawyer (Ed.), The Cambridge Handbook of the Learning Sciences (pp. 389-405). Cambridge, UK: Cambridge University Press.

Oblinger, D. G. (2004). The Next Generation of Educational Engagement. Journal of Interactive Media in Education, 8, 1-18. http://dx.doi.org/10.5334/2004-8-oblinger

Randel, J., Morris, B., Wetzel, C., \& Whitehill, B. (1992). The Effectiveness of Games for Educational Purposes: A Review of Recent Research. Simulation and Gaming, 23, 261-276. http://dx.doi.org/10.1177/1046878192233001

Winne, P. H. (1995). Inherent Details in Self-Regulated Learning. Educational Psychologist, 30, 173-187. http://dx.doi.org/10.1207/s15326985ep3004_2

Zimmerman, B. J., \& Schunk, D. H. (2004). Self-Regulating Intellectual Processes and Outcomes: A Social Cognitive Perspective. In D. Y. Dai, \& R. J. Sternberg (Eds.), Motivation, Emotion, and Cognition: Integrative Perspectives on Intellectual Functioning and Development (pp. 323-349). Mahwah, NJ: Erlbaum. 